\title{
Removal of Eriochrome Black T from water using a chitosan/zeolite composite: a kinetic study
}

\author{
Remoción de negro de Eriocromo T de agua utilizando un material compuesto a base \\ de quitosano/zeolita: un estudio cinético
}

\begin{abstract}
Héctor Manuel Guzmán Grijalva ${ }^{1 *}$, Juana Alvarado Ibarra², Martín Francisco Zamarrón Pulé1, Javier Esquer Peralta ${ }^{1}$
1 Departamento de Ingeniería Industrial, Universidad de Sonora. Boulevard Luis Encinas y Rosales S/N. Colonia Centro, CP 83000, Hermosillo, Sonora, México.

2 Departamento de Investigación en Polímeros y Materiales, Universidad de Sonora. Boulevard Luis Encinas y Rosales S/N. Colonia Centro, CP 83000, Hermosillo, Sonora, México.
\end{abstract}

\section{ABSTRACT}

A composite material was prepared using chitosan and chabazite for the removal of Eriochrome T black dye from water. Scanning electron microscopy (SEM) analyses showed chabazite particles embedded in the chitosan matrix. Thermogravimetric analyses indicated that chitosan degrades chemically at temperatures above $225^{\circ} \mathrm{C}$; chabazite only experiences weight decrease due to moisture loss. Fourier transform infrared spectroscopy (FTIR) analyses on chitosan detected the presence of $\mathrm{O}-\mathrm{H}, \mathrm{N}-\mathrm{H}, \mathrm{C}-\mathrm{H}, \mathrm{C}-\mathrm{N}$ and $\mathrm{C}-\mathrm{O}$ bonds, protonated amino groups and saccharides. In chabazite, $\mathrm{H}_{2} \mathrm{O}$ molecules, $\mathrm{T}-\mathrm{O}$ and O-T-O groups, where " $\mathrm{T}$ " corresponds to $\mathrm{Si}$ or $\mathrm{Al}$ atoms, isolated $\mathrm{H}$-bonded $\mathrm{O}-\mathrm{H}$ groups, and $\mathrm{Si}-\mathrm{O}-\mathrm{Si}$ groups were detected. In kinetic experiments, an $86 \%$ decrease of the dye concentration in solution was achieved in approximately 500 minutes. The linearization method was used to evaluate the fit of the experimental data with the pseudo-first-order, pseudo-second order, Elovich and intra-particle diffusion adsorption kinetic models. The kinetic experiments showed that the sorption mechanism corresponds to a pseudo-second order model.

Keywords: adsorption, composite, chitosan, chabazite, kinetic model

\section{RESUMEN}

Se preparó un material compuesto utilizando quitosano y chabazita para la eliminación del colorante negro eriocromo T del agua. Los análisis de microscopía electrónica de barrido (SEM) mostraron que las partículas de chabazita se incrustaron en la matriz de quitosano. Los análisis termogravimétricos indicaron que el quitosano se degrada químicamente a temperaturas superiores a $225^{\circ} \mathrm{C}$; la chabazita sólo experimenta una disminución de peso debido a la pérdida de humedad. Los análisis de espectroscopia infrarroja por transformada de Fourier (FTIR) en el quitosano detectaron la presencia de enlaces $\mathrm{O}-\mathrm{H}, \mathrm{N}-\mathrm{H}, \mathrm{C}-\mathrm{H}, \mathrm{C}-\mathrm{N}$ y C-O, grupos amino protonados y sacáridos. En la chabazita se detectaron moléculas de $\mathrm{H}_{2} \mathrm{O}$, grupos T-O y O-T-O, donde la "T" corresponde a átomos de $\mathrm{Si}$ o Al, grupos $\mathrm{O}-\mathrm{H}$ aislados y con enlaces $\mathrm{H}, \mathrm{y}$ grupos Si-O-Si. En los experimentos cinéticos, se logró una disminución del $86 \%$ de la concentración de colorante en la solución en aproximadamente 500 minutos. Se utilizó el método de linealización para evaluar el ajuste de los datos experimentales con los modelos cinéticos de adsorción de pseudo-primer orden, pseudo-segundo orden, Elovich y difusión intra-partícula. Los experimentos cinéticos mostraron que el mecanismo de sorción corresponde a un modelo de pseudo-segundo orden.

Palabras clave: adsorción, material compuesto, quitosano, chabazita, modelo cinético

\section{INTRODUCTION}

The textile industry employs large amounts of water for dyeing and washing processes, generating large volumes of effluents (Cestarolli et al., 2019). It is estimated that between 10 and $15 \%$ of dyes used do not adhere to the textile fibers and are released into the environment (Lakhan et al., 2015).

Dyes are classified based on chemical structure, source, solubility, and use (Gürses et al., 2016). In particular, azo-type dyes are synthetic compounds widely used in textile industry because of their stability to light, and resistance to microbial degradation and to fading in washing processes. Nevertheless, they are also toxic, mutagenic, cancerogenic and harmful to marine life and photosynthetic processes of aquatic plants (Álvarez et al., 2015). Eriochrome T black is an azo-type colorant used in the textile industry for dyeing silk, wool, and nylon fibers after pretreatment with chromium salts (Moeinpour et al., 2014; Karimi et al., 2018) that has been found to be particularly dangerous and carcinogenic; compounds generated from its degradation, such as naphthoquinone, are carcinogenic to an even greater degree (Khurana et al., 2018). For these reasons, the development of efficient, low-cost adsorbents for the removal of colorants such as Eriochrome T black from aqueous solutions is of the utmost importance (Park et al., 2018).

Among the numerous investigations on biological, chemical, and physicochemical treatments for the removal of colorants in water, adsorption stands out as one of the most promising methods (Tran et al., 2015). Adsorption consists of removing substances initially dissolved in a liquid or gas phase by their accumulation in an adsorbent material

*Autor para correspondencia: Héctor Manuel Guzmán Grijalva Correo electrónico: hector.guzman@unison.mx

Recibido: 10 de abril de 2021 Aceptado: 18 de agosto de 2021 
(Oladoja et al., 2017). Compared to other techniques, adsorption offers significant advantages such as high availability of materials and equipment, relatively low cost, easy operation, good contaminant removal efficiency, and effectiveness ( Uddin, 2017). Its effectiveness depends on parameters such as sorbent particle size and surface morphology, $\mathrm{pH}$, temperature, and concentration of the water to be treated (Ahmad et al., 2015).

Some of the materials most commonly used as adsorbents are silica gel, alumina and activated carbon. However, zeolites have been widely used to remove pollutants present in water by exhibiting a vast internal microporous surface in relation to the external one, and high adsorption capacity in addition to ion exchange properties (Li et al., 2015).

On the other hand, the application of chitosan, a polycationic polysaccharide, in water treatment has been exceptionally advantageous and constitutes an alternative to commonly used adsorbent materials (Kumar et al., 2018). Chitosan derives from chitin and is very easy to obtain since it mainly comes from the waste of the fishing industry (Kyzas and Bikiaris, 2015). It is remarkably versatile and can be modified in different ways or combined with other types of materials to increase its adsorption capacity. However, it is also susceptible to $\mathrm{pH}$, has inadequate mechanical strength, and has low thermal stability (Lou and Deng, 2019). Chitosan-zeolite composites combine the physical properties of their components to obtain new structural or functional properties. In particular, zeolite improves the mechanical strength of the resulting material by becoming the dispersed phase within the chitosan polymeric matrix (Flores, 2015). This research project aims to evaluate, in kinetic terms, the performance of a chitosan-chabazite composite in removing the colorant Eriochrome Black T from water by using bench tests.

\section{MATERIALS AND METHODS}

Only analytical grade reagents and deionized water were used in the experiments conducted in this research. Low molecular weight deacetylated chitosan, acetic acid, and sodium hydroxide were supplied by Sigma-Aldrich, Fermont and J.T. Baker, respectively. Chabazite type zeolite was obtained from a natural deposit located in the state of Sonora, Mexico. Indicator grade Eriochrome Black T (EBT) colorant from Sigma-Aldrich was used to prepare a $50 \mathrm{ppm}$ stock solution with deionized water. $0.25 \mathrm{M}$ sodium hydroxide and $5 \%(\mathrm{v} / \mathrm{v})$ acetic acid solutions were used to produce the composite material.

\section{Preparation of chabazite}

A sample of chabazite was ground using a hand mortar and then sifted to obtain 100-mesh size particles. Subsequently, the mineral was rinsed twice in a beaker with deionized water, each episode with a duration of 10 min during which shaking was provided. Afterwards, the mixture was let standing still to allow the settling of chabazite particles so that decantation could be used to separate them. Chabazite sample was then dried for $24 \mathrm{~h}$ at $60^{\circ} \mathrm{C}$ and a product in the form of flakes was finally obtained. Chabazite was ground once more with a hand mortar as to obtain a fine powder.

\section{Preparation of composite}

Composite was prepared using the technique described by Perez et al. (2016). The procedure involves the dissolution of $3 \mathrm{~g}$ of chitosan in $50 \mathrm{~mL}$ of a $5 \%(\mathrm{v} / \mathrm{v})$ acetic solution to obtain a chitosan solution. Separately, $3 \mathrm{~g}$ of chabazite were mixed with $20 \mathrm{ml}$ of deionized water. Both mixtures were stirred separately for $20 \mathrm{~min}$ and then mixed. The resulting mixture was agitated at $60^{\circ} \mathrm{C}$ for 4 hours using a magnetic bar spinning at 1,200 rpm. After stirring, the chitosan and chabazite mixture was added drop by drop to $500 \mathrm{~mL}$ of $0.25 \mathrm{M} \mathrm{NaOH}$ solution. This mixture was stirred for 3 hours using a magnetic bar spinning at $200 \mathrm{rpm}$ while solid beads of composite formed within the mixture. Beads were separated by filtration from the liquid phase and rinsed several times with deionized water to be finally dried at $45^{\circ} \mathrm{C}$ for 48 hours.

\section{Composite characterization}

In order to know the surface morphology of the material, Scanning Elector Microscopy (SEM) technique was employed using an equipment JEOL, model JSM-5410LV. The presence of specific structural units at a molecular level was analyzed using a Perkin Elmer Frontier Fourier-transform infrared (FTIR) spectrometer. Physical and chemical thermic-related changes in material structure were analyzed utilizing a Perkin Elmer Pyris TGA Thermogravimetric Analyzer. The procedure consisted of placing $2.52 \pm 0.19 \mathrm{mg}$ of sample in a ceramic sample holder and heating it to 900 , at a rate of 10 per minute, in an atmosphere of nitrogen and dry air, using a $20 \mathrm{~mL} \mathrm{~min}^{-1}$ flow.

\section{Kinetic experiments and models}

A $50 \mathrm{ppm}$ stock solution of colorant was prepared. 20 aliquots of $15 \mathrm{~mL}$ each were added to $50 \mathrm{~mL}$ flasks containing $0.5 \mathrm{~g}$ of composite and constant agitation was immediately provided. A different contact time between the colorant solution and the composite was assigned to each flask as to obtain a sorption curve. Aliquots' final eriochrome black $T$ concentrations for each contact time were determined using a Lambda 20 scanning double-beam spectrometer for the UV/Vis range from Perkin Elmer at a $\lambda_{\max }=570 \mathrm{~nm}$.

\section{RESULTS AND DISCUSSION}

Two or more constituents with distinct characteristics form composites, one of them acting as the matrix (bulk phase) and the rest as reinforcement (dispersed phase). Components essentially maintain and complement their properties after combining. In composites, the weakness of the matrix is reduced with the assistance of the appropriate filler (Taaca and Vasquez Jr., 2017). The importance of composites ensues from the variety of their applications. 
Chitosan is a linear copolymer of linked $\beta-(1,4)$ glucosamine molecules that can be easily obtained (figure 1) by the deacetylation reaction of the acetoamide groups in chitin using an alkaline solution (Szatkowski et al., 2015). This reaction produces a high quantity of amino groups, situated at the $\mathrm{C}-2$ position, that can be protonated and interact with organic dyes, like anionic azo-type, and many metals anions (Saha et al., 2010). The electrolytic and chelating ability of chitosan is determined by the protonation degree of the group ( $\mathrm{pK}=6.3$ ), which is dependent on $\mathrm{pH}$ (Dambies et al., 2001; An and Dultz, 2007). At $\mathrm{pH}<6.3$, the free amino groups become protonated and positively charged. At a $\mathrm{pH}$ $>6.3$, amino groups deprotonate, and chitosan exhibits no charge. Additionally, two more reactive functional groups are present in the chitosan polymeric chain, namely, the primary and secondary hydroxyl groups, at the C -3 and C -6 positions, respectively. The $\mathrm{OH}$ groups, as the amino groups, also act as coordination and reaction sites for transition metals, organic species and dyes.

Zeolites are microporous minerals with a framework formed by aluminate and silicate tetrahedra that share vertexes. The presence of the aluminum atoms creates a negative charge in the porous structure that leads to the adsorption of a variety of easily exchangeable cations, such as $\mathrm{Na}^{+}, \mathrm{K}^{+}, \mathrm{Ca}^{2+}$, and $\mathrm{Mg}^{2+}$, that in turn, can become attached to negatively charged molecules (Bailie et al., 2001; Moienpour et al., 2014; Montalvo et al., 2020). When incorporated as the dispersed phase of a composite, zeolites can provide a rigid and stable structure to the resulting material (Taaca and Vasquez Jr., 2017). The high positive density of chitosan and zeolite favors de adsorption process of anionic dyes like EBT (Moeinpour et al., 2014; Attallah et al., 2016).

\section{Morphological analyses}

Figure 2 shows, with an increasing level of magnification, the particle morphology of the composite material that was obtained. Amplifications in images 2A), 2B), 2C), and 2D) are 50X, $1000 \mathrm{X}, 2000 \mathrm{X}$, and $5000 \mathrm{X}$, respectively. In figure $2 \mathrm{~A})$, chabazite encrustations corresponding to chabazite particles becoming encapsulated into the polymeric chitosan matrix can be seen on the surface of the composite material. The formation of an uneven surface is attributable to a relatively high proportion of zeolite with respect to chitosan, making zeolite more accessible in the composite ( $2 \mathrm{~A}, \mathrm{~B}$, and C). The absence of porosity despite the presence of zeolite has been cited as a consequence of evaporative drying being used as part of the composite preparation process, ultimately leading to the obstruction of zeolite microporous (Djelad et al., 2016). The level of detail that was finally obtained allowed chabazite rhombohedral crystals to be noticeable.

\section{Functional groups identification}

Curves showing absorbance variation for the range of $500 \mathrm{~cm}^{-1}$ to $4,000 \mathrm{~cm}^{-1}$ from FTIR analyses of composite and chitosan are shown in figure 3 . In the chitosan spectrum, the structural units present, identified by the wave number of their bands, are the following: $\mathrm{O}-\mathrm{H}$ and $\mathrm{N}-\mathrm{H}$ centered around $3360 \mathrm{~cm}^{-1}$, characteristic of alcohols, amines, and amides present in the deacetylated solid structure; $\mathrm{C}-\mathrm{H}$ at $2880 \mathrm{~cm}^{-1}$, protonated amino group at $1585 \mathrm{~cm}^{-1}$, saccharide unit of chitosan at $1148 \mathrm{~cm}^{-1}$, and C-N and C-O at $1029 \mathrm{~cm}^{-1}$ (Bashir et al., 2019). For chabazite, it has been reported two types of building units vibrations are characteristic; some corresponding to $\mathrm{O}-\mathrm{T}-\mathrm{O}$ symmetric, and asymmetric stretching and bending, and those related to T-O-T linkages that involved a bridging oxygen atom; where $\mathrm{T}$ designates a $\mathrm{Si}$ or $\mathrm{Al}$ atom in the chabazite $\mathrm{TO}_{4}$ tetrahedral building unit (Dimowa et al., 2018), with strong bands associated to $\mathrm{Si}-\mathrm{O}-\mathrm{Si}$ and $\mathrm{Si}-\mathrm{O}-\mathrm{Al}$ groups vibrations are located in the wavelength region of 700 to $1200 \mathrm{~cm}^{-1}$. Also, a band at roughly $1650 \mathrm{~cm}^{-1}$ represents the bending vibration of $\mathrm{H}_{2} \mathrm{O}$ molecules and $\mathrm{T}-\mathrm{O}$ stretching (Falk, 1984; Dimowa et al., 2018) and those at approximately 3670

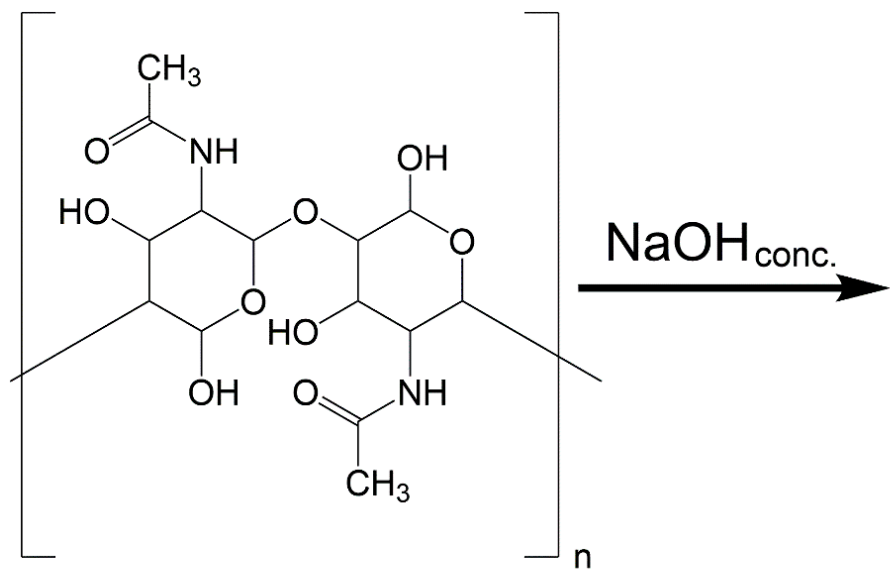

Chitin

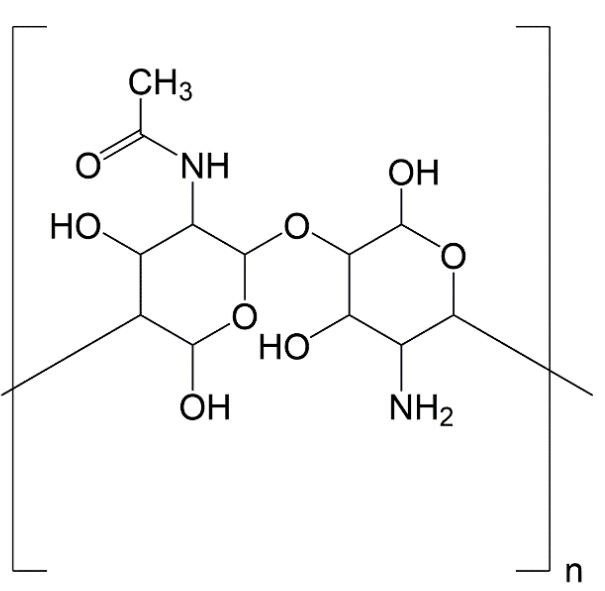

Chitosan

Figure 1. Schematic depiction of the chitin deacetylation reaction to form chitosan based on the representation from Szatkowski et al., 2013.

Figura 1. Descripción esquemática de la reacción de desacetilación de quitina para formar quitosano basada en la representación de Szatkowski et al., 2013. 

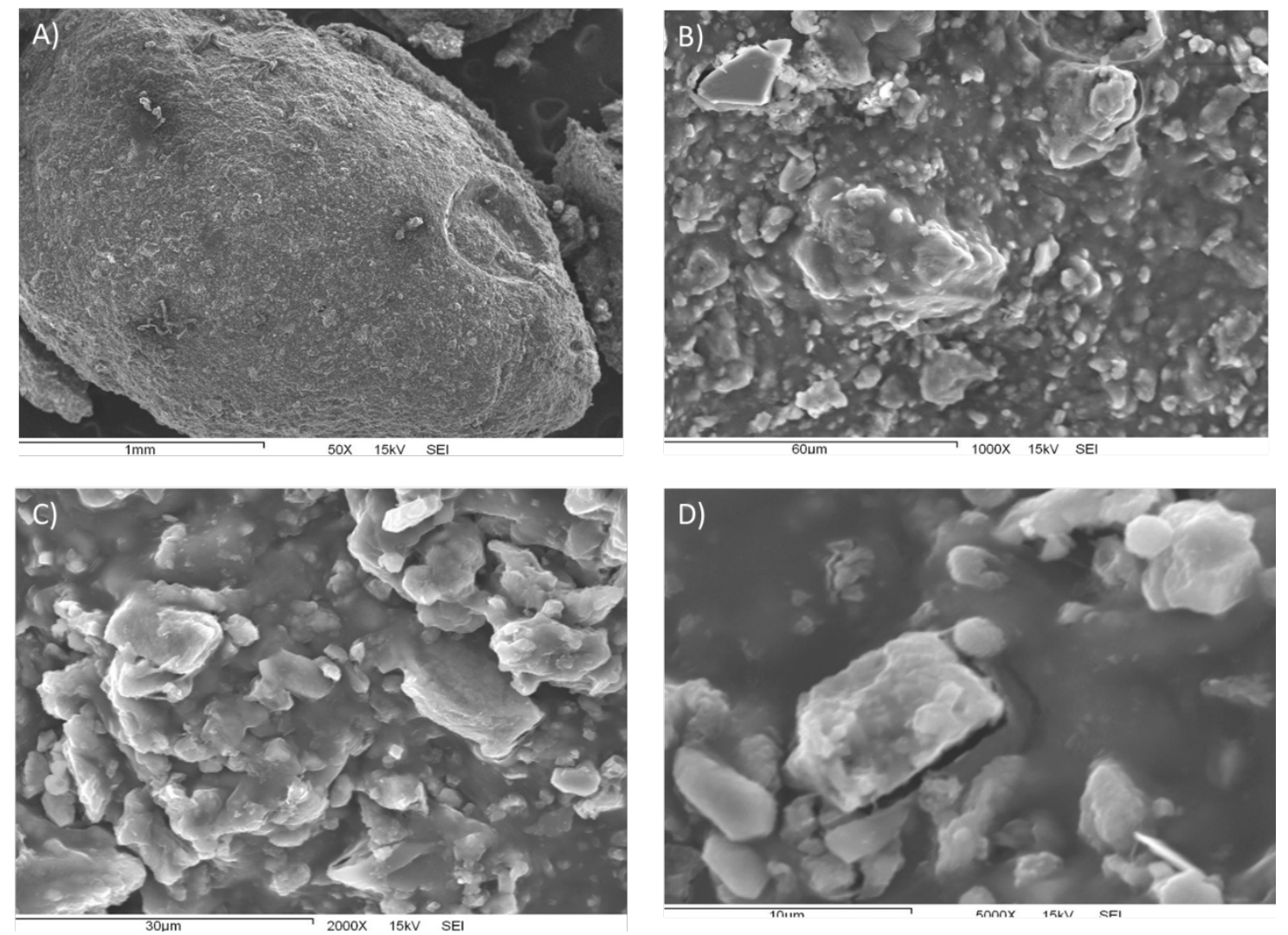

Figure 2. SEM image showing the morphology of the composite using a magnification of A) $50 \mathrm{X}, \mathrm{B}) 1000 \mathrm{X}, \mathrm{C}) 2000 \mathrm{X}$, and D) $5000 \mathrm{X}$.

Figura 2. Imagen de MEB que muestra la morfología del material compuesto empleando una amplificación de A) 50 X, B) 1 $000 \mathrm{X}, \mathrm{C}) 2000 \mathrm{X}$ y D) $5000 \mathrm{X}$.

and $3450 \mathrm{~cm}^{-1}$ denote isolated and $\mathrm{H}$-bonded $\mathrm{O}-\mathrm{H}$ stretching, respectively (Aysan et al., 2019). Bands corresponding to 6 membered rings are located between 570 and $635 \mathrm{~cm}^{-1} ; \mathrm{H}_{2} \mathrm{O}$ bending and T-O stretching at approximately 1660 and 1044 $\mathrm{cm}^{-1}$, respectively, isolated and $\mathrm{H}$-bonded $\mathrm{O}-\mathrm{H}$ stretching at 3669 and $3443 \mathrm{~cm}^{-1}$, respectively, and external T-O at $762 \mathrm{~cm}^{-1}$ (Aysan et al., 2016).

The composite spectrum shows peaks at approximately 3360,2880 , and $1585 \mathrm{~cm}^{-1}$ like chitosan, and at 1650 $\mathrm{cm}^{-1}$ similarly to chabazite. The peak at approximately 1,030 $\mathrm{cm}^{-1}$ coincides with bands of both, chitosan and zeolite, located in the vicinity of that value.

\section{Thermal stability results}

The results of the thermo-gravimetric analysis shed light on the thermo-resistance of the composite material and determine the temperature at which changes affecting its chemical structure occur. The progressive weight loss that ensued as temperature increased is shown in figure 4 . Three important stages can be identified along the curve describing the weight decrement associated with temperature increase; the first one takes place between $30{ }^{\circ} \mathrm{C}$ and $225^{\circ} \mathrm{C}$ and corresponds to a $12.5 \%$ weight reduction in the composite material originated by moisture loss. This was followed by a significant decrease of up to $24.5 \%$ between $225^{\circ} \mathrm{C}$ to $455^{\circ} \mathrm{C}$, that becomes particularly abrupt at $275^{\circ} \mathrm{C}$, that relates to the degradation of the saccharides in the molecular structure of the chitosan. Finally, the last stage occurs when temperature increases from $455^{\circ} \mathrm{C}$ to $790^{\circ} \mathrm{C}$, and leads to the final decomposition of the material at approximately $680^{\circ} \mathrm{C}$. This behavior is in accordance with what was reported by Escobar et al. (2013), and Djelad et al. (2016).

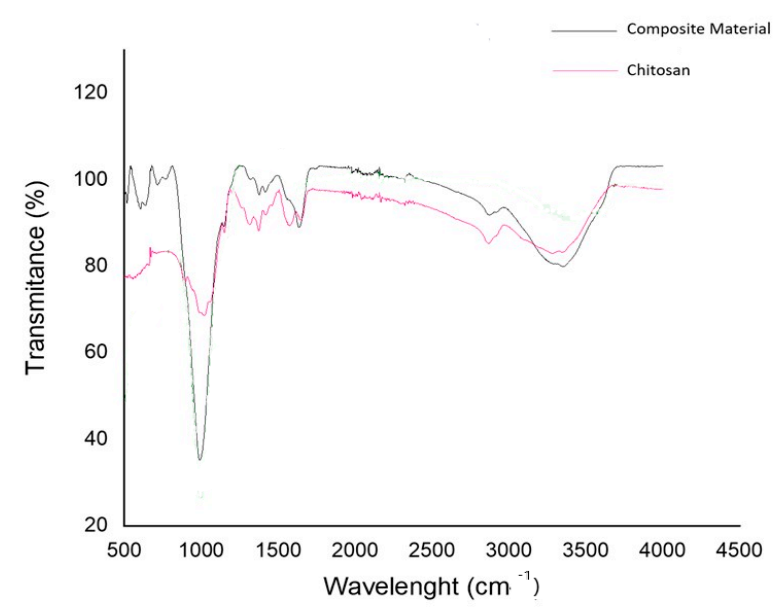

Figure 3. FTIR spectrums of chitosan and composite.

Figura 3. Espectros FTIR del quitosano y el material compuesto. 


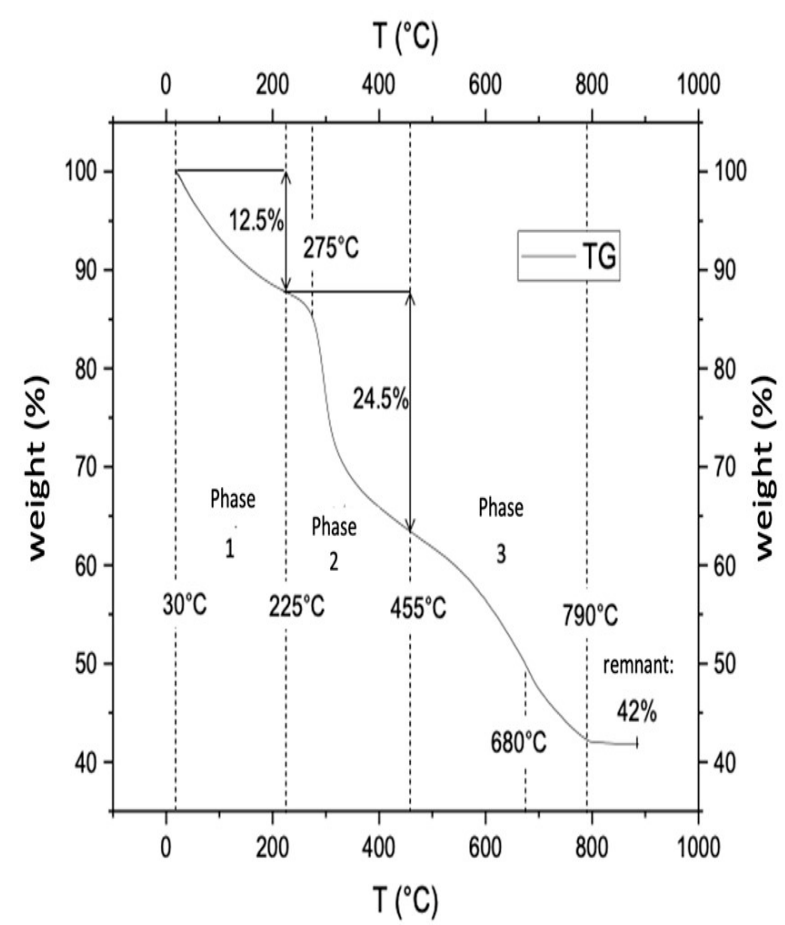

Figure 4. Weight reduction for composite material obtained from the thermogravimetric analysis results.

Figura 4. Pérdida de peso del material compuesto obtenida de los resultados de los análisis termogravimétricos.

The analysis shows that dry chabazite accounts for $42 \%$ of the total mass of the composite material. This can be seen more clearly in figure 5 , where the paths of weight loss through time obtained from thermogravimetric analyses performed on separate samples of zeolite, composite material and chitosan are shown graphically. The curve on the top reveals that the total weight reduction for zeolite came to be approximately $15 \%$ of its initial value. The curve describes the gradual loss of weight that took place as temperature rose from 25 to $300^{\circ} \mathrm{C}$ and the stabilization of sample weight that ensued from this point up to $900{ }^{\circ} \mathrm{C}$. The noticeable absence of inflection points denotes that only one mechanism is responsible for the initial weight loss, namely, loss of humidity, and that no chemical transformations in zeolite structure that involve the release of gaseous compounds ever occurred. Curves corresponding to composite material and chitosan, exhibit a similar shape, though chitosan curve, previously shown with more detail in figure 4 , is much steeper than that of the composite. The temperatures at which inflection points are located along these two curves are strikingly similar up to $400^{\circ} \mathrm{C}$; above it, the inflection points in the composite material curve are shown at a higher temperature than in that of chitosan. This seems to indicate that chitosan, when being an integral part of the composite, degrades at a slower rate than pure chitosan at high temperatures.

\section{Adsorption kinetics}

Experimental data, were analyzed using the linearized forms of the equations corresponding to pseudo-first order

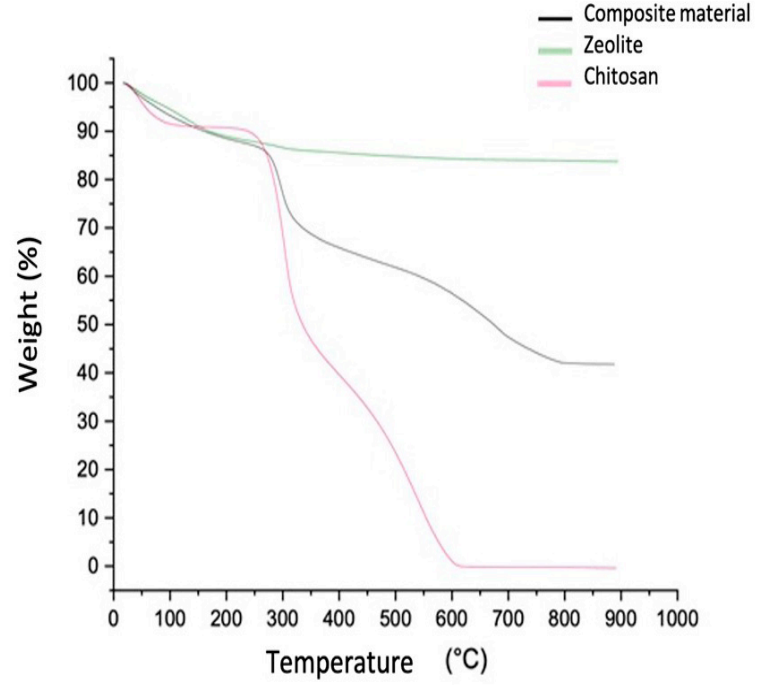

Figure 5. Chart showing the path of weight reduction for zeolite, composite and chitosan obtained from the thermogravimetric analyses results.

Figura 5. Gráfica de la pérdida de peso de la zeolita, el material compuesto y el quitosano obtenida de los resultados de los análisis termogravimétricos.

(PFO) (Lagergren and Vetenskapsakademiens, 1898); the pseudo-second order (PSO), the intraparticle diffusion (IP), and the Elovich models.

The equation for Lagergren's pseudo-first order model is:

$$
\operatorname{In}\left(q_{e}-q_{t}\right)=\ln q_{e}-k_{1} t
$$

Where $q_{e}(\mathrm{mg} / \mathrm{g})$ designates the concentration of colorant in the composite material once equilibrium has been reached and $q_{t}(\mathrm{mg} / \mathrm{g})$ to the solid phase concentration at a particular time $t(\mathrm{~min})$, while $k_{1}\left(\mathrm{~min}^{-1}\right)$ denotes the first-order rate constant.

Assumptions made regarding this model are: 1) adsorption takes place exclusively in specific sites and adsorbed ions do not interact with one another; 2 ) adsorption energy is not determined by surface coverage; 3 ) only a monolayer of adsorbate can be formed on sorbent surface and, consequently, a saturated monolayer constitutes the maximum level of adsorption that can be attained, 4) adsorbate concentration is essentially constant, and 5) adsorbate sorption obeys a first-order rate equation (Largitte and Pasquier, 2016).

The equation describing the PSO kinetics model, developed by Ho and McKay (1999), is:

$$
\frac{t}{q_{t}}=\frac{1}{k_{2} q_{e}^{2}}+\frac{t}{q_{e}}
$$

In which $k_{2}\left(\mathrm{~g} \mathrm{mg}^{-1} \mathrm{~min}^{-1}\right)$ designates the PSO rate constant and the rest of the variables have the same meaning as in the first-order rate equation. According to this model, adsorption rate depends on the number of active sites 
available on the solute surface, being the difference between solid phase concentration at equilibrium and its value at any particular time prior to reaching that state, the driving force behind the process (Kajjumba et al., 2018).

Sorption data from systems that conforms to the IP model fit the following equation:

$$
q_{t}=k_{p} t^{0.5}+C
$$

If such is the case, by plotting $q_{t}$ values versus $t^{0.5}$, a straight line, with a slope equal to $k_{p}$ and with the value for $C$ being given by intersection with axis $y$, will be obtained. $k_{p}$ $\left(\mathrm{mg} \mathrm{g}^{-1} \mathrm{~min}^{-0.5}\right)$, is the IP diffusion rate constant, and $C\left(\mathrm{mg} \mathrm{g}^{-1}\right)$ is a parameter related to boundary layer thickness.

This model is used to determine if one particular step of the adsorption process controls adsorption rate; three stages being considered. The first one, referred to as film diffusion, relates to sorbate gradual migration from boundary layer to sorbent surface. Then, adsorbate internal diffusion into pores comes about, followed by its final attachment to active sorption sites inside pores (Pholosi et al., 2020). Which stage exerts a higher influence in the adsorption process depends on system conditions. In systems with very limited agitation and low concentration, film diffusion acts as the rate controlling step; otherwise, the adsorption is controlled by IP diffusion.

According to the Elovich model, adsorption is ruled by the equation:

$$
q_{t}=\frac{1}{\beta} \ln (\beta \alpha)+\frac{1}{\beta} \ln t
$$

Where $\alpha\left(\mathrm{mg} \mathrm{g}^{-1} \mathrm{~min}^{-1}\right)$ is the initial adsorption rate, while $\beta\left(\mathrm{g} \mathrm{mg}^{-1}\right)$ is desorption constant. This model assumes that solute concentration decreases exponentially while the amount of solute adsorbed increases (Kajjumba et al., 2018).

Data obtained from kinetic experiments consisted of colorant concentration values in the liquid phase measured at different times, when the solution initial concentration, $\mathrm{pH}$ and volume were kept constant, as well as the amount of sorbent used. Figure 6 shows the decrease in the liquid concentration of Eriochrome Black T colorant with time when 15 $\mathrm{mL}$ of a $50 \mathrm{ppm}$ solution were placed in contact with $0.5 \mathrm{~g}$ of composite material. The concentration of the solution once equilibrium was reached was approximately $7.0 \mathrm{ppm}$ and that of sorbent $4.25 \mathrm{mg} \mathrm{g}^{-1}$. This represents an $86 \%$ reduction of solution dye concentration in approximately 500 minutes and implies that the material has the capacity of appreciably removing Eriochrome Black $T$ dye from water.

The extent to which the values derived from experimental information actually fitted a straight line, when the linearized forms of the equations describing each particular kinetic model were considered, was assessed by plotting $\ln \left(q_{e}-q_{t}\right) v s t$ for the PFO model case, and $\frac{t}{q_{t}} v s t, q_{t} v s t^{0.5}$ and $q_{t}$ vs $\ln t$ for the PSO, IP, and Elovich models, respectively. The appropriateness of data distributions fitting to a straight line

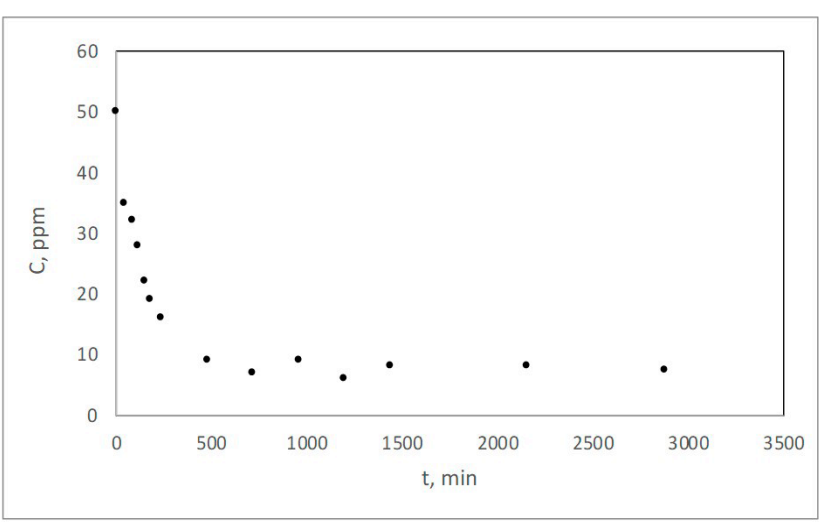

Figure 6. Change in solution dye concentration with time in the kinetic experiments.

Figura 6. Cambio en la concentración de la solución de colorante a través del tiempo en los experimentos cinéticos.

was evaluated using linear regression analysis. The values of the linear correlation coefficient, $\mathrm{R}$, obtained in each case are shown in the respective plots (figure 7 ).

The PFO and PSO models have been commonly used to characterize the nature of an adsorption process. Neither of these two approaches take into account the effect of mass diffusion in relation to the adsorption/desorption process, but rather they are based on the consideration that it is the rate at which the sorbate interacts with the sorbent surface, and the type of that interaction, assumed to be inherently irreversible in nature, that actually controls the sorption kinetics (Plazinski et al, 2013). For systems that fit the PFO adsorption model, it is believed that the adsorbate binds to the sorbent surface through physisorption, whereas chemisorption is the mechanism associated with a PSO model. The surface reactions that schematically show the attachment of sorbate to the surface for the PFO and PSO respectively, can be represented by the following equations (Largitte and Pasquier, 2016):

$$
\begin{aligned}
& S+M \rightarrow M S \\
& 2 S+M \rightarrow M(S)_{2}
\end{aligned}
$$

Equation 5 also depicts the kinetic mechanism taking place in accordance to the Elovich approach, although this model assumes sorbed ions interact via chemisorption with the solid surface and that adsorption rate decreases as surface coverage increases. Chemisorption implies the formation of a chemical bond due to the transfer or sharing of electrons between sorbate and sorbent. Physisorption involves weak electrostatic attraction forces and no modification of sorbent chemical structure. Therefore, to evaluate the importance of diffusion, it is necessary to resort to other models, such as the IP model.

From the analysis of the experimental results, it turned out that the strength of the linear relationships of the data distributions, as measured by the coefficient of determination, $r^{2}$, yielded an acceptable value only when the linearized 
form of the PSO model equation was used (figure 7), being 0.9992. This suggests that the process is governed by a second order reaction mechanism for which the general assumptions belonging to the PFO model apply. As mentioned above, it has been claimed that the fit of the data to a PSO
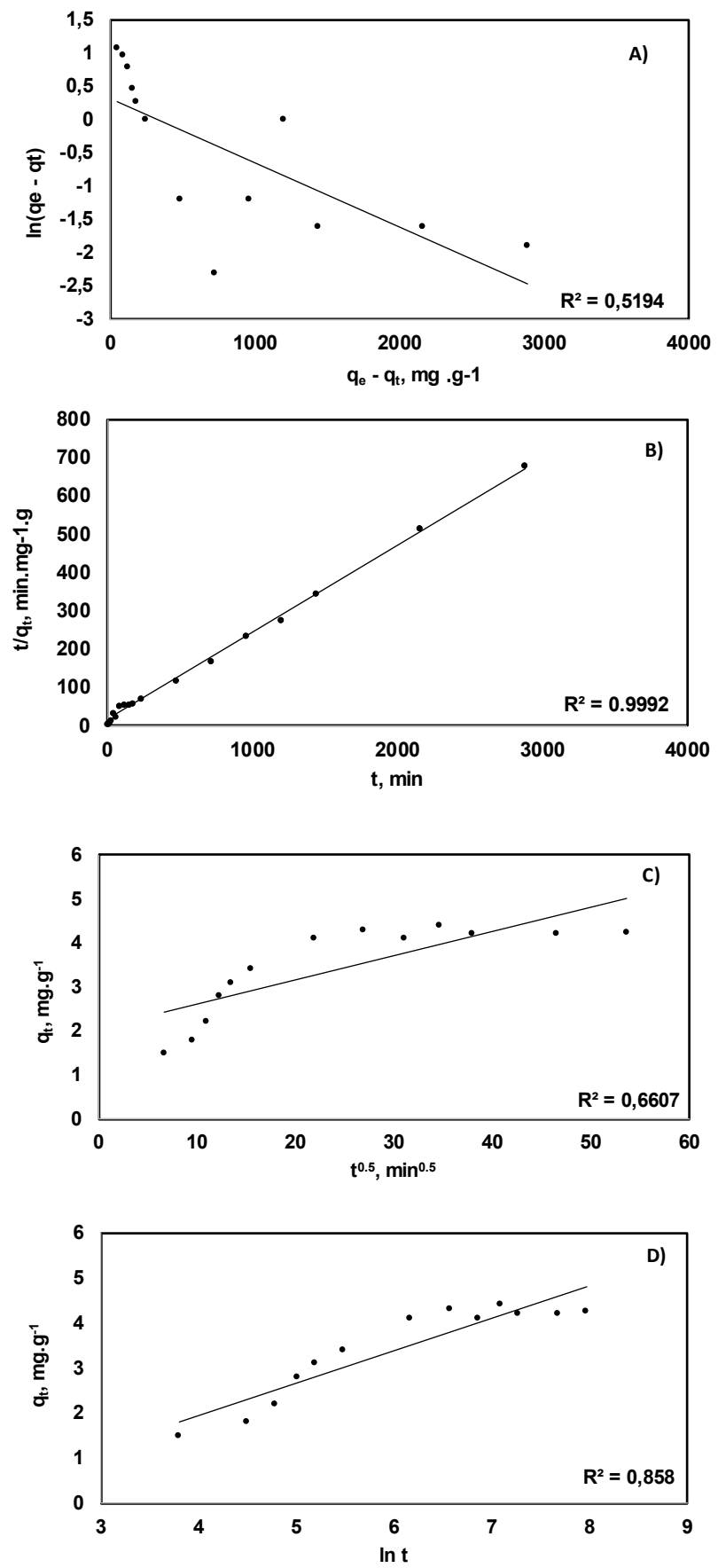

Figure 7. Charts showing the plotting of data derived from experimental results according to the linearized forms of the PSF order (A), PSO (B), IP (C), and Elovich (D) equations; straight lines obtained from linear regression analysis are also on view.

Figura 7. Distribución de los datos obtenidos a partir de los resultados experimentales según las formas linearizadas de las ecuaciones de pseudoprimer orden (A), pseudo-segundo orden (B), difusión intraparticular (C) y Elovich (D); las rectas obtenidas a partir de análisis de regresión lineal también se muestran. model is indicative that chemisorption is the mechanism controlling adsorption; although this is not a generally accepted assessment and has been refuted by some researchers on the grounds that such a fact is not sufficient evidence of the formation of a chemical bond between sorbate and sorbent. Instead, initial concentration levels have been attributed a more decisive role in explaining the observed adsorption mechanisms; with the PSO process favored by low sorbate concentrations and PFO by high ones (Azizian, 2004).

Adjustment of data to the linearized form of the Elovich model yielded the second highest valued for $\mathrm{r}^{2}, 0.858$. Despite being lower than 0.9 , which is considered a statically acceptable value to derive conclusions, this further corroborates, the presence of chemisorption as the main binding mechanism of sorbate to sorbent sorption. On what comes to the IP model, the low value of $r^{2}$ that was obtained can be in response to the mechanical stirring provided during the experiments, which eliminated the possibility of diffusion being the limiting stage in the adsorption process.

\section{CONCLUSIONS}

The chitosan-chabazite composite obtained and studied in this research showed to have the capacity of appreciably removing Eriochrome Black T colorant from water. Evidence shows that the mechanisms controlling the adsorption process fits a PSO model under the conditions prevailing during the experiments. This may be the result of the low initial dye concentration that was used and of the formation of bonds of chemical nature between sorbate and sorbent.

\section{ACKNOLEDGEMENTS}

The authors would like to kindly thank Dr. Ramón Alfonso Moreno Corral and Dr. Silvia Elena Burruel Ibarra, from the Department of Polymer and Materials Research at the University of Sonora, for their invaluable help in performing the UV-vis and SEM analyses, respectively.

\section{REFERENCES}

Ahmad, M., Ahmed, S., Swami, B. and Ikram, S. 2015. Adsorption of heavy metals ions: role of chitosan and cellulose for water treatment. International Journal of Pharmacognosy. 2: 280289.

Álvarez, L., Valdez, R., García, R., Olivo, D., Garza, M, Meza, E. and Gortárez, P. 2015. Decolorization and biogas production by an anaerobic consortium: effect of different azo dyes and quinoid redox mediators. Water Science and Technology. 72: 794-801.

An, J., Dultz, S. 2006. Adsorption of tannic acid on chitosanmontmorillonite as a function of $\mathrm{pH}$ and surface charge properties. Applied Clay Science. 36: 256-264.

Attallah, O. A., Al-Ghobashy, M. A., Nebsen, M. and Salem, M. Y. 2016. Removal of cationic and anionic dyes from aqueous solution with magnetite/pectin and magnretite/silica/ pectin hybrid nanocomposites: kinetic, isotherm and mechanism analysis. RSC Advances. 6: 11461-11480. 
Aysan, H., Edebali, S., Ozdemir, C., Celik, M. and Karakaya, N. 2016. Use of chabazite, a natural abundant zeolite, for the investigation of the adsorption kinetics and mechanism of methylene blue dye. Microporous and Mesoporous Materials. 235: 78-86.

Azizian, S. 2004. Kinetic models of sorption: a theoretical analysis. Journal of Colloid and Interface Science. 276: 47-52.

Bailie, J.E., Hutchings, G.J. and O'Leary, S. 2001. Supported Catalyst. In Encyclopedia of Materials: Science and Technology. K. H. J. Buschow, R. W. Cahn, M. C. Flemings, B. Ilschner, E. J. Kramer, S. Mahajan and P. Veyssière (ed.), pp. 8986-8990. Elsevier, Oxford.

Bashir, S., Teo, Y. Y., Ramesh, K. and Rizwan, M. 2019. Synthesis and Characterization of $\mathrm{pH}$-sensitive $\mathrm{N}$-succinyl chitosan hydrogel and its properties for biomedical applications. Journal of the Chilean Chemical Society. 64: 4571-4574.

Cestarolli, D., das Graças de Oliveira, A. and Guerra, E. 2019. Removal of eriochrome black textile dye from aqueous solution by combined electrocoagulation-electroflotation methodology. Applied Water Science. 9: 101.

Dambies, L., Guimon, C., Yiacoumi, S. and Guibal, E. 2001. Characterization of metal ion interactions with chitosan by X-ray photoelectron spectroscopy. Colloid Surface A. 177: 203-214.

Djelad, A., Morsli, A., Robitzer, M., Bengueddach, A., Di Renzo, F. and Quignard, F. 2016. Sorption of $\mathrm{Cu}$ (II) lons on ChitosanZeolite X Composites: Impact on Gelling and Drying Conditions. Molecules. 21: 1 - 15.

Dimowa, L., Piroeva, I., Atanasova, V., Rusew, R. and Shivachec, B. 2018. Structural peculiarities of natural chabazite modified by $\mathrm{ZnCl}_{2}$ and $\mathrm{NiCl}_{2}$. Bulgarian Chemical Communications. 50: 114-122.

Escobar-Sierra, D., Ossa-Orozco, C., Quintana-Rodríguez, M. and Ospina-Villa, W. 2013. Optimización de un protocolo de extracción de de quitina y quitisano desde caparazones de crustáceos. Scientia et Technica. 18: 260-266.

Falk, M. 1984. The frequency of the $\mathrm{H}-\mathrm{O}-\mathrm{H}$ bending fundamental in solids and liquids. Spectrochimica Acta Part A: Molecular Spectroscopy. 40: 43-48.

Flores, A. 2015. Estudios de equilibrio de adsorción de fluoruros sobre compositos a base de quitosano. Masters dissertation. Universidad Autónoma de San Luis Potosí, San Luis Potosí.

Gürses, A., Acikyildiz, M., Günes, K. and Gürses, M. 2016. Dyes and Pigments. Springer. Switzerland.

Ho, Y.S. and McKay, G. 1999. Pseudo-Second Order Model for Sorption Processes. Process Biochemistry. 34: 451-465.

Kajjumba, G., Emik, S., Ongen, A., Kurtulus, H. and Aydin, S. 2018. Modelling of Adsorption Kinetic Processes - Errors, Theory and Application. At: Advanced Sorption Process Applications. Serpil Edebali (ed.). IntechOpen Limited, London.

Karimi, M., Mahdavinia, G., Massoumi, B., Baghban, A. and Saraei, M. 2018. lonically crosslinked magnetic chitosan/kcarrageenan bioadsorbents for removal of anionic eriochrome black-T. International Journal of Biological Macromolecules. 113: 361-375.
Khurana, I., Shaw, A., Bharti, Khurana, J. and Rai, P., 2018. Batch and dynamic adsorption of eriochrome black-T from water on magnetic graphene oxide: experimental and theoretical studies. Journal of Environmental Chemical Engineering. 6: 468-477.

Kumar, S., Prasad, K., Gil, J., Sobral, A. and Khon, J. 2018. Mesoporous zeolite-chitosan composite for enhanced capture and catalytic activity in chemical fixation of $\mathrm{CO}_{2}$. Carbohydrate Polymers. 198: 401-406.

Kyzas, G. and Bikiaris, D. 2015. Recent modifications of chitosan for adsorption applications: a critical and systematic review. Marine Drugs. 13: 312-337.

Lagergren S. and Vetenskapsakademiens K. S. 1898. Zur theorie der sogenannten adsorption gelster stoffe. Handlingar. 24:1-39.

Lakhan, R., Kumar, P. and Pratap, R. 2015. Enzymatic decolorization and degradation of azo dyes-a review. International Biodeterioration \& Biodegradation. 104: 21-31.

Largitte, L. and Pasquier, R. 2016. A review of the kinetics adsorption models and their application to the adsorption of lead by an activated carbon. Chemical Engineering Research and Design. 109: 495-504.

Li, J., Corma, A. and Yu, J. 2015. Synthesis of new zeolite structures. Royal Society of Chemistry. 44: 7112-7121.

Lou, X. and Deng, F. 2018. Nanomaterials for the removal of Pollutants and Resource reutilization. $1^{\text {st }}$ ed. Elsevier.

Moeinpour, F., Alimoradi, A. and Kazemi, M. 2014. Efficient removal of eriochrome black-T from aqueous solution using $\mathrm{NiFe}_{2} \mathrm{O}_{4}$ magnetic nanoparticles. Journal of Environmental Health Science and Engineering. 12:1

Montalvo, S., Huiliñir, C., Borja, R., Sánchez, E. and Herrmann, C. 2020. Application of zeolites for biological treatment processes of solid wastes and wastewaters - A review. Bioresource Technology. 301: 1-10.

Oladoja, N., Unuabonah, E., Amuda, O. and Kolawole, O. 2017. Operational principles and material requirements for coagulation/flocculation and adsorption-based watBer treatment operations. Polysaccharides as a Green and Sustainable Resources for Water and Wastewater Treatment. 1-11.

Park, J., Wang, J., Tafti, N. and Delaune, R. 2018. Removal of eriochrome black $\mathrm{T}$ by sulfate radical generated from Feimpregnated biochar/persulfate in fenton-like reaction. Journal of Industrial and Engineering Chemistry.

Pérez, A., Díaz, P., Rangel, J., Cerino, F., Ovando, V. and Alcalá, J. 2016. Fluoride adsorption capacity of composites based on chitosan-zeolite-algae. Revista Mexicana de Ingeniería Química. 15: 139-147.

Pholosi, A., Naidoo, E. B. and Ofomaja, A. E. 2020. Intraparticle diffusion of $\mathrm{Cr}(\mathrm{VI})$ through biomass and magnetite coatedbiomass: A comparative kinetic and diffusion studys. South African Journal of Chemical Engineering. 32: 39-55.

Plazinski, W., Dziuba, J. and Rudzinski, W. 2013. Modeling of sorption kinetics: the pseudo-second order equation and the sorbate intraparticle diffusivity. Adsorption. 19: 10551064. 
Saha, T. K., Bhoumik, N. C., Karmaker, S., Ahmed, M. G., Ichikawa, H. and Fukumori, Y. 2010. Adsorption of Methyl Orange onto chitosan from aqueous solution. Journal of Water Resource and Protection. 2: 298-906.

Szatkowski, T., Kołodziejczak-Radzimska, A., Zdarta, J., SzwarcRzepka, K., Paukszta, D., Wysokowski, M., Ehrlich, H. and Jesionowski, T. 2015. Synthesis and characterization of hydroxyapatite/chitosan composites. Physicochemical Problems of Mineral Processing. 51: 575-585.
Taaca, K. L. M. and Vasquez, M. R. 2017. Fabrication of Agexchanged zeolite/chitosan composites and effects of plasma treatment. Microporous and Mesoporous Materials. 241: 383-291.

Tran, V., Ngo, H., Guo, W., Zhang, J., Liang, S., Ton-That, C. and Zhang, X. 2015. Typical low-cost bio sorbents for adsorptive removal of specific organic pollutants from water. Bioresource Technology. 182: 353-363.

Uddin, M. 2017. A review on the adsorption of heavy metals by clay minerals, with special focus on the past decade. Chemical Engineering Journal. 308: 438-462. 